\title{
A Septuaginta em língua portuguesa na tradução de Frederico Lourenço
}

\author{
Anderson de Oliveira Lima*
}

\section{Resumo}

As páginas a seguir apresentam aos leitores uma breve introdução à Septuaginta (LXX), a Bíblia em língua grego que foi produzida no século II a.C. e que era a versão mais lida nos dias de Jesus, tendo determinado fortemente o desenvolvimento dos primeiros cristianismos. Nossa pesquisa celebra a publicação inédita dessa importante obra em língua portuguesa pela editora Companbia das Letras, uma nova versão bíblica com a tradução completa da Septuaginta que constitui o enorme projeto do linguista português Frederico Lourenço, que está traduzindo e publicando gradualmente toda a coleção em oito volumes. Ao estudá-la, nosso objetivo é analisar a obra a partir de sua materialidade, sempre considerando seus paratextos e as características singulares dessa obra em sua versão brasileira.

Palavras-chave: Bíblia de Lourenço; Frederico Lourenço; Crítica literária; Tradução bíblica; Septuaginta.

\section{Frederico Lourenço's Portuguese Translation of The Septuagint}

\section{Abstract}

The following pages present to the readers a brief introduction to the Septuagint (LXX), the Bible in Greek language that was made around the second century B.C.E. and was read by the Jesus' time, which had strongly conditioned the development of the early Christianity. Our research celebrates the publication of this important work in Portuguese by Companbia das Letras, a new biblical version with the complete Septuagint's translate which is the huge project of Frederico Lourenço, a Portuguese linguist who is gradually translating and publishing all the collection in six volumes. Studying that work, our goal is to know the book from its materiality, always considering its paratexts and the singular characteristics of the Brazilian version.

Key-words: Bible of Lourenço; Frederico Lourenço; Literary criticism; Biblical translation; Septuagint.

* Doutor em Ciências da Religião (UMESP) e doutor em Letras (Mackenzie), graduado em Música e em Letras, especialista (Lato-Sensu) em Bíblia (UMESP). Também possui pósdoutorado em Ciências da Religião (PUC-Campinas) e atualmente é pós-doutorando em Estudos Comparados de Literaturas de Língua Portuguesa (USP).

anderson.angela.lima@gmail.com 


\section{La Septuaginta en portugués en la traducción de Frederico Lourenço}

\section{Resumen}

Las siguientes páginas presentan a los lectores una breve introducción a la Septuaginta (LXX), la Biblia en lengua griega que se produjo en el siglo II a. C. y fue la versión más leída en los días de Jesús, habiendo determinado firmemente el desarrollo del cristianismo primitivo. Nuestra investigación celebra la publicación inédita de este importante trabajo en portugués por la Companhia das Letras, una nueva versión bíblica con la traducción completa de la Septuaginta que constituye el enorme proyecto del lingüista portugués Frederico Lourenço, quien está traduciendo y publicando gradualmente la colección completa en ocho volúmenes. Nuestro objetivo es analizar el trabajo desde su materialidad, siempre considerando sus paratextos y las características únicas de este trabajo en su versión brasileña.

Palavras-clave: Biblia de Lourenço; Frederico Lourenço; Crítica literaria; Traducción bíblica; Septuaginta.

\section{Introdução}

Desde 2017 a editora Companhia das Letras tem publicado no Brasil os volumes que fazem parte de uma nova tradução da Bíblia para a língua portuguesa que está sendo desenvolvida pelo linguista Frederico Lourenço, professor da Universidade de Coimbra, a partir dos textos gregos. A obra, já premiada em Portugal, ${ }^{1}$ é um empreendimento de grandes proporções cujas particularidades interessam não somente a religiosos, mas especialmente a estudantes, teólogos, historiadores, linguistas e críticos literários. São justamente essas particularidades que nos levaram a desenvolver uma pesquisa duradoura sobre a Bíblia de Lourenço, ${ }^{2}$ um trabalho cujos resultados serão (parcialmente) apresentados nas páginas seguintes.

Até aqui, o que o leitor brasileiro tem em mãos são os três primeiros volumes de uma coleção que, no total, promete ocupar seis (dois deles com dois tomos cada), somando algumas milhares de páginas. O primeiro desses volumes

\footnotetext{
Por ocasião da publicação do primeiro volume, Frederico Lourenço recebeu a homenagem do Prêmio Pessoa, uma condecoração concedida anualmente a uma personalidade portuguesa por seu destaque na carreira acadêmica, artística ou literária. Leia mais em: <https:// www.publico.pt/2016/12/09/culturaipsilon/noticia/-e-o-premio-pessoa-2016-1754215>; $<$ https://www.dn.pt/artes/interior/frederico-lourenco-vence-premio-pessoa-5542902. html>. Acesso em 26/08/2019.

2 A pesquisa sobre a Bíblia de Lourenço está sendo desenvolvida como parte de um projeto de pós-doutorado em Estudos Comparados de Literaturas de Lingua-Portuguesa que estamos realizando, desde março de 2019, através do Departamento de Letras Clássicas e Vernáculas da Universidade de São Paulo.
} 
nos trouxe a nova tradução dos quatro evangelhos que compõem o cânone do Novo Testamento cristão (BÍBLIA, V. I, 2017). Publicado primeiro pela editora Quetzal no ano de 2016, o primeiro volume com a nova tradução logo foi considerado o "acontecimento editorial do ano" (MILHAZES, 2017) e, em 2019, já havia vendido mais de trinta e dois mil exemplares em Portugal. ${ }^{3}$ Este sucesso editorial imediatamente foi adaptado ao português brasileiro e chegou ao nosso mercado pela Companhia das Letras um ano depois. ${ }^{4}$ A repercussão midiática local foi considerável, especialmente porque coincidiu razoavelmente com a visita do tradutor ao país para participar da $15^{\text {a }}$ Feira Literária de Paraty (Flip). ${ }^{5}$ O segundo volume (BÍBLIA, V. II, 2018), contendo os demais livros do Novo Testamento, foi publicado no Brasil no ano seguinte e o terceiro (BÍBLIA, V. III, 2019), formado pela coleção dos livros dos Profetas, chegou até nós em abril de 2019, suscitando novas discussões concernentes à obra.

Acontece que o tradutor, por ser um especialista na língua grega - que já era conhecido no Brasil por suas traduções da obra homérica -, ${ }^{6}$ escolheu produzir uma tradução do Antigo Testamento que parte de uma versão que difere daquela que cristãos e judeus conhecem de seus livros sagrados: ele está a traduzir a Septuaginta, uma antiga tradução dos textos hebraicos para o grego que nasceu em meados do século III a.C. e que, embora tenha sido decisiva na vida de judeus da diáspora e dos primeiros cristãos, caiu em desuso após o fechamento do cânone hebraico pelos judeus em fins do século I d.C. e após a popularização da Vulgata latina de São Jerônimo, produzida entre os séculos IV e V, no seio do cristianismo.

3 Segundo matéria publicada pelo jornal português Diário de Notícias em 18 fevereiro de 2019: <https://www.dn.pt/cultura/interior/tem-duvidas-sobre-latim-frederico-lourencofez-uma-nova-gramatica-10590328.html>. Acesso em 17/09/2019.

4 Uma segunda edição deste primeiro volume foi lançada em Portugal 2018, anunciando um texto revisado e aumentado. Todavia, as diferenças entre as edições são discretas: o tradutor considerou uma edição mais atual do texto grego de Nestlé/Aland, alterou algumas poucas passagens bem pontuais e acrescentou um anexo com novas notas sobre cada um dos evangelhos.

5 Citamos, a seguir, alguns dos registros da participação de Lourenço na Flip em 2017: <https://www.publishnews.com.br/materias/2017/05/04/frederico-lourenco-na-flip-2017>; $<$ https://www.atribuna.com.br/2.713/tradutor-da-b\%C3\%ADblia-portugu\%C3\%AAsfrederico-louren \%C3\%A7o-participa-da-flip-1.23662> Acesso em 26/08/2019.

6 Lourenço traduziu para a língua portuguesa tanto a Ilíada (HOMERO, 2013) quanto a Odisseia (HOMERO, 2011), obras que também foram publicadas no Brasil pela Companhia das Letras. A editora também publicou as adaptações dessas mesmas obras para leitores jovens, e a lista completa dos títulos está disponível no site da editora: < https://www. companhiadasletras.com.br/autor.php?codigo=03013>. Acesso em 26/08/2019. 
A Septuaginta, a despeito de sua importância na história do judaísmo e no desenvolvimento dos cristianismos originários, nunca foi traduzida para a língua portuguesa e sua tradução, desejada pelos estudiosos, talvez confunda os leitores cristãos que agora poderão adquirir uma Bíblia que, com sinceridade, não traz os livros nas versões que as religiões elegeram para seus respectivos cânones. Se já haviam dúvidas quanto à legitimidade de um tradutor da Bíblia que não é religioso ${ }^{7}$ - Frederico Lourenço é, confessadamente, agnóstico e gay (LOURENÇO, 2017, p. 12, 19, 73) -, o que pensar de uma edição do Antigo Testamento que não teve como texto base a versão hebraica e os testemunhos manuscritos do chamado Texto Massorético? ${ }^{8}$ Como lidar com uma tradução que faz emergir um tipo de texto bíblico que, por várias razões, se tentou esquecer? Indo além, o que dizer de uma Bíblia que não foi produzida por tradutores, comentadores e editores ligados à religião; uma Bíblia que não se anuncia como texto sagrado e cuja edição é obra de uma editora secular como a Companhia das Letras? A quem se destina tal livro? Qual seu lugar no mercado editorial e qual seu valor para os leitores brasileiros?

As páginas seguintes têm por objetivo apresentar a Bíblia de Lourenço (especialmente seu terceiro volume) de maneira introdutória, discutindo suas particularidades por meio de um referencial teórico que nos convida a uma crítica atenta às formas, à materialidade da obra, à produção de sentidos produzida pelo conjunto de seus paratextos e às idiossincrasias da tradução.

Leia-se, por exemplo, a crítica do Frei Herculano Alves, franciscano capuchinho e professor de Sagrada Escritura na Universidade Católica do Porto, que questiona o fato de o tradutor, por não ser religioso nem ter formação superior em Teologia ou Ciências Bíblicas, não fazer uso de um "vocabulário próprio" que ele esperava encontrar na tradução da obra que, de seu ponto de vista, não pode ser outra coisa além de "o livro da fé de um povo, dirigido a um povo de fé": <https://observador.pt/opiniao/uma-nova-traducao-dabiblia/>. Acesso em 27/08/2019.

8 Desde o estabelecimento do cânone em fins do século I d.C., os judeus adotaram os textos hebraicos como suas Escrituras. Os testemunhos manuscritos que melhor preservam essa tradição literária, e dos quais partem todas as edições críticas da Bíblia Hebraica até hoje, estão na coleção de manuscritos que chamamos de Texto Massorético (TM), os quais foram produzidos por volta do século X por copistas judeus excepcionalmente criteriosos (FRANCISCO, 2003, p. 131, 146-153). Os cristãos, que nos primeiros séculos usaram preferencialmente a Septuaginta, substituíram seu uso pela tradução latina de São Jerônimo a partir do século IV (a Vulgata), até que os interesses mudaram no Renascimento e surgiu a demanda por textos críticos nos idiomas originais do Antigo Testamento e por traduções mais fidedignas, o que os levou a valorizar, também, os textos hebraicos e, consequentemente, o Texto Massorético. 


\section{$1 \mathrm{O}$ texto grego da Septuaginta}

Desde que o reino de Judá foi devastado pelo babilônios entre os séculos VII e VI a.C., sucessivas gerações de judeus viveram em comunidades formadas fora das terras sagradas de seus descendentes. Com o passar do tempo, eles deixaram de se comunicar por meio do idioma de seus ancestrais e, no caso dos muitos judeus sediados em Alexandria (sob o controle dos Ptolomeus, que herdaram o território após a inauguração do período belenístico pelas invasões de Alexandre Magno), era de se esperar que assumissem o grego como língua corrente e desejassem ler seus antigos textos sagrados no mesmo idioma. Dessa necessidade surgiu, em meados do século III a.C., a Septuaginta, obra que, até onde se sabe, foi a primeira tradução dos textos do Antigo Testamento (escritos originalmente em hebraico e aramaico) para um outro idioma.

O nome Septuaginta (ou LXX) nos remete à lenda que conta que o Pentateuco (os primeiros cinco livros da Bíblia, tradicionalmente ligados à memória de Moisés) teria sido traduzido por 72 eruditos que trabalharam, cada um numa cela individual, por 72 dias ininterruptos e produziram 72 traduções milagrosamente idênticas (BÍBLIA, V. III, 2019, p. 12). Depois, outros livros já celebrados que concorriam para assegurar um lugar no futuro cânone judaico foram sendo traduzidos até meados do século II a.C. - com diferentes estilos e níveis de liberdade ou literalidade - e acrescidos à coletânea que, ao cabo, terminou por se fixar com 53 livros (SEPTUAGINTA, 2006, p. lxxx).

Tudo indica que os judeus, de modo geral, aprovavam a Septuaginta e "escritores judeus como filo e Josefo fizeram uso da LXX, se não de forma exclusiva, pelo menos de modo preponderante" (SEPTUAGINTA, 2006, p. Ixxxi). Por um bom tempo, os judeus fizeram da LXX um importante instrumento de preservação da cultura judaica nas comunidades estabelecidas na diáspora e a utilizaram, também, para a difusão do próprio judaísmo entre os gentios.

O cristianismo nasceu, como sabemos, sob a forma de uma seita judaica. Consequentemente, os cristãos das primeiras gerações tinham a Septuaginta como suas Escrituras e foi pela leitura que dela fizeram que extraíram os elementos que, de seu ponto de vista, caracterizavam o messias, o ungido (Cristo) que, segundo as profecias, um dia viria da parte de Deus para devolver a seu povo o poder e a dignidade perdidos. Assim sendo, a Septuaginta pode ser lida como a principal das fontes de onde emanavam as esperanças messiânicas que fizeram surgir a figura de Jesus Cristo, o personagem dos evangelhos. 
Embora os textos do Antigo Testamento grego não sejam sagrados para nenhum grupo religioso contemporâneo, essa relação com as origens do cristianismo (e também do judaísmo rabínico, que nasce quando a oposição à seita cristã já era uma realidade) preservam sua importância para historiadores e estudiosos das ricas produções textuais daqueles dias:

Sobretudo para historiadores dos primeiros séculos do cristianismo, o conhecimento do Antigo Testamento na versão grega dos Septuaginta afigurase obrigatório. Isso porque o Antigo Testamento pressuposto pelo Novo Testamento, e citado no Novo Testamento, é o Antigo Testamento grego. (BÍBLIA, V. III, 2019, p. 10)

Um exemplo clássico da maneira como os primeiros cristãos se apropriaram da Septuaginta para desenvolver sua própria vertente do judaísmo está no modo como usaram a versão grega de Isaías 7.14: É conhecida a opinião de que a LXX traduziu de maneira equivocada o texto do profeta Isaías ao substituir a palavra hebraica almah, que significa apenas "mulher jovem", por parthénos, "que designa uma jovem solteira que pode ser (ou não) virgem” (BÍBLIA, V. I, 2017, p. 28-29). Certo ou não, é evidente que certos judeus desenvolveram, com base na LXX, a expectativa por um messias que nasceria, milagrosamente, de uma mulher virgem, como nos deixa ver a história da infância que abre o Evangelho de Mateus (cap. 1), escrito no final do século I, que provavelmente cria para Jesus a biografia mais condizente com o imaginário religioso dos primeiros cristãos. Se para os adeptos daquela vertente do protocristianismo o nascimento de Jesus coincidia com o texto sagrado e legitimava sua identidade messiânica, para outros judeus parecia evidente que os mitos sobre Jesus Cristo foram criados por conta de más leituras que, por sua vez, podem ter sido motivadas pelos erros dos tradutores da Bíblia grega. Não por acaso, os judeus passaram, pouco a pouco, a rejeitar a Bíblia grega - que ficou mais e mais identificada com cristãos - fazendo um retorno aos textos hebraicos que culminou, pelos fins do século I, na Palestina, no estabelecimento do cânone da Bíblia Hebraica, a Tanakh.

Do ponto de vista da Crítica Textual (ou da ecdótica), a versão que temos da Septuaginta é bastante fidedigna, isto é, não diferirá significativamente daquela que foi lida pelos primeiros cristãos. Considere-se, por exemplo, que o texto hebraico do Antigo Testamento de que se utilizam os estudiosos e os religiosos se baseia em manuscritos produzidos por volta dos séculos X e XI d.C. O manuscrito mais importante de que dispõem é o Códice de Leningrado, 
um documento datado pelo próprio escriba no ano de 1008 que preserva, com excelente grau de confiabilidade, a versão mais antiga do Texto Massorético (GEISLER; NIX, 1997, p. 135-137). A LXX, por sua vez, ainda que não tenha se beneficiado de uma instituição forte e duradoura por trás do estabelecimento de sua coleção - como ocorre com os cânones religiosos - possui testemunhos bem mais antigos. A versão mais antiga parte principalmente de valiosos códices do século IV: o Códice Sinaítico e o Códice Vaticano (ALAND; ALAND, 2009, p. 175-176; PAROSCHI, 2003, p. 47-50), manuscritos que, aliás, são também os mais importantes para o trabalho de reconstituição do texto grego do Novo Testamento (BÍBLIA, V. II, 2018, p. 28-29).

Além dos testemunhos citados, são conhecidas outras versões do texto do Antigo Testamento em grego. A mais importante para os estudos da Septuaginta é a tradução produzida por Teodócio (ou Teodocião) no segundo século d.C. Ele teria se baseado na Septuaginta, mas a corrigiu em muitos pontos a partir da comparação com os textos hebraicos valorizados em seu tempo. Ademais, outras traduções independentes e recensões foram produzidas com finalidades diferentes, com destaque para as seguintes: a tradução literal de Áquila, destinada à incipiente escola rabínica de início do segundo século; a tradução de Símaco, também do século II; a tradução de Orígenes, do século III, presente em sua monumental Héxapla, obra que apresentava o texto bíblico em seis colunas e versões diferentes; e a recensão de Luciano, que se tornou muito popular até a ascensão da Vulgata no século IV (SEPTUAGINTA, 2006, p. 1xxx-1xxxviii).

As novas gerações têm acessado a Septuaginta principalmente pelo texto estabelecido pela edição crítica de Alfred Rahlfs, trabalho que se tornou padrão para a leitura da Septuaginta desde sua publicação em 1935, em Stuttgart. Recentemente, a edição de Rahlfs passou por uma revisão "superficial" sob a supervisão de Robert Hanhart com o objetivo de corrigir erros de edição e impressão. Contudo, segundo a Sociedade Bíblica Alemã, o texto grego e o aparato crítico foram modificados em mais de mil lugares, dando origem a uma nova edição padrão para o estudo da Septuaginta em 2006, texto que passou a ser conhecido como a edição de Rahlfs-Hanhart (SEPTUAGINTA, 2006, p. 1xxv-lxxvii). ${ }^{10}$

\footnotetext{
9 Leia a descrição da obra no site da instituição: <https://www.die-bibel.de/en/ shop/originaltexte/altes-testament/septuaginta-5119>. Acesso em 05/09/2019.

10 E é relevante que se saiba, quanto à Septuaginta de Rahlfs-Hanhart, que ela tem sido impressa no Brasil pela Sociedade Bíblica - e com prefácios em português - desde 2015.
} 
Para sua tradução ao português, Frederico Lourenço está trabalhando sobre a edição de Rahlfs, de 1935, e não a partir da nova edição de RahlfsHanhart, de 2006, como era de se esperar. ${ }^{11}$ Esta, porém, não parece ter sido uma decisão consciente, mas uma negligência do tradutor que, tomando o livro que tinha mãos, não se deu ao trabalho de procurar por novas edições antes de iniciar a tradução. Esse mesmo descuido já havia sido cometido pelo tradutor anteriormente, quando traduziu todo o Novo Testamento fazendo uso de uma edição crítica de 1979, ao passo que dispomos, desde 2012, de uma nova edição (a vigésima oitava) do Novum Testamentum Graece de NestleAland (LIMA, 2018, p. 322). Este problema relativo ao texto grego usado por Lourenço na tradução do Novo Testamento foi parcialmente resolvido: ele publicou em Portugal, em 2018, uma segunda edição do primeiro volume de sua Bíblia, uma edição "revista e aumentada" que substitui o texto grego de 1979 pelo de 2012 (ao menos) na bibliografia (BÍBLIA, V. I, 2018, p. 441). O tradutor, portanto, reconheceu o erro e talvez também publique novas edições dos demais volumes após revisões que considerem os textos estabelecidos por edições críticas mais recentes.

\section{Particularidades da Bíblia de Frederico Lourenço}

Neste item, colocaremos nossa atenção sobre alguns elementos que, do modo como os entendemos, tornam essa Bíblia em seis volumes um produto diferente e digno de nossa atenção. Trataremos brevemente, e com poucos exemplos, das características da tradução, de aspectos físicos relativos aos livros e suas edições portuguesa e brasileira e, por fim, daquilo que se oferece ao leitor sob a forma de paratextos (todo conteúdo que emoldura o conteúdo, que posto ao redor de um texto existe para apresentar, controlar, adaptar um texto ao suporte que o comporta com a finalidade de melhor transmiti-lo ao leitor). Trago à memória do leitor que, especificamente neste artigo, temos concentrado nossa atenção sobre o último volume publicado no Brasil, pois é nele que encontramos a versão de Lourenço da Septuaginta, a obra que, por hora, nos interessa mais.

\footnotetext{
11 Além citar, na bibliografia, a edição de Rahlfs, de 1935 (BÍBLIA, V. III, 2019, p. 1003), Lourenço concedeu uma entrevista em vídeo em que declara ter feito cópias do livro que pertente à biblioteca da Universidade de Coimbra e que está a produzir sua tradução a partir dela: <https://www.youtube.com/watch?v=JkiR4b9BYS0\&feature=youtu.be $>$. Acesso em 05/09/2019.
} 
Um primeiro elemento que precisa ser lembrado e levado em consideração para que se compreenda a Bíblia de Lourenço é que estamos tratando de uma Bíblia produzida a partir de pressupostos acadêmicos por um tradutor e comentarista que não possui qualquer vinculação religiosa. Este é um fato realmente raro na história da Bíblia como livro, um fato que nos levou, algures, a apresentar a Bíblia de Lourenço como uma "Bíblia laica" (LIMA, 2018).

Frederico Lourenço esboça o tipo de leitura que considera ideal para a obra na Introdução do terceiro volume, dizendo repetidamente que seu objetivo é proporcionar uma leitura "historicamente informada" (BÍBLIA, V. III, 2019, p. 17, 20, 39). Isto é, ele quer que o leitor esteja interessado e minimamente atento às importantes datas que marcaram a história de Israel no tempo em que os livros da LXX foram escritos (entre os séculos VIII e II a.C.), que esteja razoavelmente informado quanto às diferentes fases da redação dos livros bíblicos, quanto aos diferentes graus de confiabilidade histórica dos eventos que as narrativas nos dão a conhecer, quanto às diferentes (até divergentes) possíveis leituras permitidas por uma mesma passagem, quanto às diferenças (variantes) observáveis na comparação entre as principais versões manuscritas do texto que lê etc. Com efeito, esta é a ideia que o conduz na produção de seus paratextos:

[...] faz parte da leitura historicamente informada do Antigo Testamento estarmos atentos às fascinantes diferenças de perspectiva que os diversos livros propõem [...] São questões para as quais será chamada a atenção das leitoras e dos leitores nas introduções e nos comentários a cada livro. (BÍBLIA, V. III, 2019, p. 20)

A Bíblia de Frederico Lourenço, portanto, se destina a pessoas (religiosas ou não) que estejam interessadas numa obra de valor histórico, que se importem com o que os críticos e pesquisadores têm dito a respeito da Bíblia nos últimos séculos. Sua Bíblia extensa, dividida em seis volumes, cuja capa não anuncia uma obra "sagrada", mas apenas uma "Bíblia", não foi produzida para acompanhar fieis à igreja, para que sirva como fonte para uma leitura religiosa convencional. Antes, posicionando-se criticamente, o tradutor e comentarista oferece uma espécie de introdução aos estudos bíblicos de nível superior, o que faz de sua Bíblia um instrumento de estudos mais indicado para quem procura desenvolver uma leitura crítica ou alimenta curiosidades linguísticas e históricas. 
Outra característica relevante para todo leitor é que a tradução de Lourenço é regida pelo que se chama, entre biblistas, de princípio da correspondência formal; ou seja, é uma tradução literal, tenta ser tão fiel ao texto grego quanto possível. Ele promete: “O que as leitoras e os leitores encontram aqui em português não é nem mais nem menos do que aquilo que está no texto original" (BÍBLIA, V. I, 2017, p. 41). Para um veículo midiático, chegou a declarar:

Não facilito rigorosamente nada. A única facilidade foi a opção de transliterar as palavras gregas e, no caso do Antigo Testamento, as hebraicas, porque não coloco nada em caracteres gregos ou hebraicos. De resto, fiz tudo com o rigor de um trabalho académico, que é como considero que devo agir, enquanto professor universitário que sou. ${ }^{12}$

Privilegiando as formas do texto grego é natural que o tradutor abdique, em dados momentos, da própria compreensibilidade proporcionada por versões mais dinâmicas, assim como serão frustradas algumas expectativas de leitores que já conhecem aquelas narrativas por outras versões (FUNARI, 2018, p. 119). Isso, todavia, parece ser uma característica dessas bíblias laicas ou acadêmicas da contemporaneidade. ${ }^{13}$

Em virtude dessas preferências, na Bíblia de Frederico Lourenço é comum lermos, especialmente na leitura da Septuaginta, algumas passagens difíceis que vêm acompanhadas de notas como essa: "o significado da frase hebraica (com várias incertezas textuais) é muito discutível, pelo que não admira que, na versão grega, esse versículo assuma uma forma que, para todos os efeitos, não faz sentido", ou "Esse versículo é praticamente incompreensível em grego, situação que reflete a extrema incerteza de interpretação da correspondente frase hebraica" (BÍBLIA, V. III, p. 75, 194).

Passando a outro tema, a Bíblia de Lourenço também é a única que, por motivos que desconhecemos, começa seu Antigo Testamento só depois

12 Leia as palavras de Frederico Lourenço, transcritas a partir de uma entrevista concedida para o jornal português Diário de Notícias por ocasião do lançamento do segundo volume de sua Bíblia em Portugal: <https://www.dn.pt/artes/interior/o-ideal-seria-ler-a-bibliano-original-e-nao-na-traducao-5742154.html>. Acesso em 17/09/2019.

13 O mesmo princípio é defendido enfaticamente por Robert Alter (outro premiado tradutor) em A Bíblia em inglês e a heresia da explanação, uma longa seção da introdução que ele escreveu para a sua tradução "literária” da Bíblia Hebraica para a língua inglesa (ALTER, 2019, p. xiii-xxxix), a qual é apresentada, na orelha da nova e completa edição de 2019, como um marco, "a primeira tradução literária de autor único da Bíblia Hebraica". 
do Novo Testamento (já no volume 3) e o faz pelos livros proféticos. Nesta nova configuração do cânone o leitor encontrará, depois dos profetas, os textos sapienciais (volume 4, em dois tomos), seguidos pelos livros históricos (volume 5, em dois tomos) e, finalmente, os livros da Lei, a Torá (volume 6) (BÍBLIA, V. I, 2018, p. 445). Lendo o terceiro volume, ainda surpreenderá o leitor o fato de que o primeiro livro que essa versão nos apresenta da Septuaginta é o livro do profeta Amós. A apresentação dos livros, logo se vê, não segue qualquer dos cânones conhecidos. Todavia, em certo sentido, a sequência procura estar próxima dos critérios adotados pelos redatores da antiga Septuaginta que abriram a seção profética com o rolo dos chamados "Doze Profetas" optando, ao que parece, por alguma espécie de ordem cronológica ao colocar Oseias e Amós à frente. Assim, de maneira exclusiva, Lourenço decide abrir sua LXX por Amós por se basear na hipótese de ser este o livro mais antigo do Antigo Testamento, ou aquele cuja maior parte foi escrita no século VIII a.C. (BÍBLIA, V. III, p. 39).

Partindo sempre da versão grega mais antiga e prezando pela literalidade, a Bíblia de Lourenço não deixa de explicitar os anacronismos próprios da Bíblia grega, como exemplifica a leitura de Daniel 1.20: "E em toda a palavra e inteligência e instrução, em todas as coisas que o rei lhes perguntava, ele os tomou por dez vezes mais sábios, superando os sofistas e os filósofos em todo o seu reino" (grifos nossos). A nota a que este versículo nos conduz é de caráter informativo e segue fielmente o objetivo de auxiliar uma leitura "historicamente informada":

1,20 "sofistas [...] filósofos": a presença desses intelectuais na corte da Babilônia no século VI a.C. nos pareceria um espantoso anacronismo (numa época em que ainda não havia nem sofistas nem filósofos na própria Atenas) se não tivéssemos consciência de que, na versão grega de Êxodo 7,11, também encontramos "sofistas" na corte do faraó egípcio. Na versão de Teodócion, esses sofistas e filósofos são "encantadores e magos” e, no Texto Massorético, "magos e astrólogos" (embora a segunda palavra hebraica, ashshaph, seja de sentido discutível, pois só ocorre aqui e em 2.2 em toda a Bíblia Hebraica). Os "filósofos" podem, em alternativa, ser "filólogos" (como se lê no Papiro 967, sobre o qual ver Ezequiel 36,23-38*).

Para um último exemplo recorreremos à leitura do profeta Amós 4.13, texto que, na tradução de Frederico Lourenço, diz: "Pois eis que [sou] Eu quem fortalece o trovão e cria o vento e anuncia à Humanidade o seu ungido, fazendo a aurora e o nevoeiro e pisando os píncaros das nuvens. 
Senhor Deus Todo-Poderoso é Seu nome!". Primeiramente, que fique claro que todas as palavras iniciadas por letras maiúsculas são heranças de uma tradição tipográfica própria da impressão de Bíblias modernas, uma prática que, obviamente, sempre foi empreendida por profissionais majoritariamente religiosos. As maiúsculas são opções de tradutores e editores que desejam dar destaque a personagens e, em especial, a tudo aquilo que se refere a Deus numa espécie de reverência que se expressa tipograficamente, pela forma dada ao texto impresso. A Bíblia de Lourenço, neste aspecto, se rende à tradição e segue padrões próprios de bíblias produzidas por instituições religiosas, ainda que tais elementos não advenham da antiga tradição manuscrita.

Em segundo lugar, algumas peculiaridades da Bíblia grega se fazem notar: vê-se, por exemplo, como os nomes de Deus expressos no texto hebraico (Javé, Deus dos Exércitos) são substituídos no texto grego (Senhor, Todo-Poderoso), criando o vocabulário que posteriormente estaria presente nos discursos cristãos. E é ainda mais curioso o fato de a Septuaginta estranhamente incluir a palavra khristós (cristo = ungido) - que, a rigor, seria a tradução do hebraico mashiyach (messias = ungido) - onde o texto hebraico nada dizia sobre tal figura. Isso, sem dúvida, reflete o crescimento da expectativa messiânica entre os judaísmos de tons apocalípticos de meados do segundo século a.C., e nos ajuda a entender porque a Septuaginta foi importante no processo de construção do cristianismo que, ao cabo, é um efeito concreto dessa mesma expectativa messiânica que os textos (primeiro) relataram e (depois) impulsionaram. Em nota, Frederico Lourenço deixa sua observação a esse respeito, ao escrever: "O claro tom messiânico desse versículo no texto grego está ausente do Texto Massorético, em que à palavra grega khristós ("ungido"; cf. "Cristo") corresponde uma palavra única na Bíblia Hebraica: seach ("pensamentos"?) (BÍBLIA, V. III, 2019, p. 60).

O material paratextual da Bíblia de Lourenço, em resumo, traz vasto volume de conteúdo que explica algumas das decisões do tradutor, expões dificuldades próprias da literatura bíblica e da língua grega, traz referências históricas que possam ajudar o leitor na decifração de determinadas passagens e discute variações significativas entre as versões mais conhecidas dos textos do Antigo Testamento (a versão antiga da LXX, a versão de Teodócio e a versão da Bíblia Hebraica, que se baseia no Texto Massorético). Isso reafirma o que foi dito acima sobre ser esta uma Bíblia destinada a estudiosos e interessados, prioritariamente, em aspectos textuais, linguísticos e históricos ligados à literatura bíblica. 


\section{Considerações finais}

Não há dúvidas de que nossas poucas páginas não foram suficientes para discorrer sobre todos os aspectos que tornam a leitura da Bíblia de Frederico Lourenço (e da Companhia das Letras) uma obra interessante. Por esse motivo, deixamos ao leitor interessado o convite para que procure e também leia os demais artigos que temos produzido sequencialmente, cada um tratando dessa vasta obra de um ponto de vista diferente.

Aqui, após termos apresentado o projeto de modo geral, centramonos na análise de algumas especificidades relativas ao terceiro volume da coleção. O próprio fato de nos oferecer uma inédita tradução dos textos da Septuaginta para a língua portuguesa já é uma iniciativa que tem seus méritos e justifica esta e muitas outras produções analíticas. Surpreenderia, deveras, se os estudiosos da história do cristianismo não demonstrassem interesse por essa rica contribuição intelectual. Entretanto, o que mais valoriza a obra, de nosso ponto de vista, é modo como o texto da Bíblia grega é apresentado, o modo como é emoldurado por um grande volume de material paratextual rico em informações técnicas cujo ápice está, seguramente, nas notas de caráter linguísticos que evocam toda a experiencia do tradutor como linguista (FUNARI, 2018, p. 220-221).

Merece elogios também a iniciativa dos produtores que oferecem, com essa coleção, a melhor versão da Bíblia para aqueles que não se aproximam dela por razões religiosas. Esta Bíblia laica serve, como nenhuma outra dentre as disponíveis no Brasil, àqueles que se importam com a história e a literatura judaica de um ponto de vista estritamente acadêmico, ou que valorizam a Bíblia como patrimônio cultural e a querem ler como literatura. Trata-se de um projeto que acrescenta conteúdo para os religiosos que se interessam pelos textos bíblicos em versões eruditas e tira este importante livro do domínio religioso para o disponibilizar, numa versão nada ortodoxa, para todos os demais tipos de leitores.

\section{Referências}

ALAND, Kurt; ALAND, Barbara. O texto do Novo Testamento. São Paulo: Fonte Editorial, 2009.

ALTER, Robert. The Hebrew Bible: a translation with commentary (volume 1: the five books of Moses - Torah). New York/London: W; W; Norton \& Company, 2019.

BÍBLIA, volume I: Novo Testamento: os quatro Evangelhos. Tradução do grego, apresentação e notas por Frederico Lourenço. São Paulo: Companhia das Letras, 2017. 
BÍBLIA, volume I: Novo Testamento: os quatro Evangelhos. Tradução do grego, apresentação e notas por Frederico Lourenço - $2^{\text {a }}$ edição revista e aumentada. Lisboa: Quetzal, 2018.

BÍBLIA, volume II: Novo Testamento: apóstolos, epístolas, Apocalipse. Tradução do grego, apresentação e notas por Frederico Lourenço. São Paulo: Companhia das Letras, 2018.

BÍBLIA, volume III: Antigo Testamento: os livros proféticos. Tradução do grego, apresentação e notas por Frederico Lourenço. São Paulo: Companhia das Letras, 2019.

BÍBLIA, volume IV: Antigo Testamento: os livros sapienciais. Tradução do grego, apresentação e notas por Frederico Lourenço. Lisboa: Quetzal, 2018.

FRANCISCO, Edson de Faria. Manual da Bíblia Hebraica: introdução ao Texto Massorético. São Paulo: Edições Vida Nova, 2003.

FUNARI, Pedro Paulo A. Bíblia. Novo Testamento, os quatro evangelhos. Traduzido do grego por Frederico Lourenço. São Paulo: Companhia das Letras, 2017, 424 pp.

ISBN9788535928815. Phaos - Revista de Estudos Clássicos, v. 18, n. 1, p. 119-122, 2018.

GEISLER, Norman; NIX, William. Introdução bíblica: como a Bíblia chegou até nós. São Paulo: Vida, 1997.

GENETTE, Gérard. Paratextos editoriais. Cotia, SP: Ateliê Editorial, 2009.

HOMERO. Ilíada. Tradução e prefácio de Frederico Lourenço. São Paulo: Penguin Classics Companhia das Letras, 2013.

HOMERO. Odisseia. Tradução e prefácio de Frederico Lourenço. São Paulo: Penguin Classics Companhia das Letras, 2011.

LIMA, Anderson de Oliveira. A Bíblia de Lourenço: uma Bíblia laica. Campinas: Reflexão, v. 43, n. 2, p. 311-327, 2018.

LOURENÇO, Frederico. O livro aberto: leituras da Bíblia. Rio de Janeiro: Oficina Raquel, 2017.

LYONS, Martyn, Livro: uma história viva. São Paulo: Editora Senac São Paulo, 2011.

MCKENZIE, Donald Francis. Bibliografia e sociologia dos textos. São Paulo: Editora da Universidade de São Paulo, 2018.

MILHAZES, Ana Catarina. Bíblia - vol. I, Novo Testamento, os quatro evangelhos.

Revista Pontes de Vista, no 2; Cultureprint, 2017. Disponível em: < https://pontesdevista. wordpress.com/2017/01/18/recensao-a-frederico-lourenco-2016-biblia-vol-i-novotestamento-os-quatro-evangelhos-lisboa-quetzal/\#more-936>. Acesso em: 10/06/2019.

PAROSCHI, Wilson. Crítica textual do Novo Testamento. São Paulo: Vida Nova, 1993.

SEPTUAGINTA: Id est Vetus Testamentum graece iuxta LXX interpretes edidit Alfred Rahlfs (Editio altera quam recognovit et emendavit Robert Hanhart). Stuttgart: Deutsche Bibelgesellschaft, 2006.

Submetido em: 9-3-2020

Aceito em: 1-6-2021 